\title{
Factors affecting hookah tobacco smoking among females in the Islamic Republic of Iran: a qualitative study
}

Mohammad Rafi Bazrafshan, ${ }^{1}$ Amir Mansouri, ${ }^{2}$ Hamed Delam, ${ }^{3}$ Behnam Masmouei ${ }^{4}$ and Nasrin Shokrpour ${ }^{5}$

${ }^{1}$ Department of Nursing, School of Nursing, Larestan University of Medical Sciences, Larestan, Iran. ${ }^{2}$ Department of Paramedical School, Gerash University of Medical Sciences, Gerash, Iran. ${ }^{3}$ Student Research Committee, Larestan University of Medical Sciences, Larestan, Iran. ${ }^{4}$ School of Nursing Hazrat Zahra (P.B.U.H) Abadeh, Shiraz University of Medical Sciences, Shiraz, Iran. ${ }^{5}$ Shiraz University of Medical Sciences, Shiraz, Iran. (Correspondence to: Mohammad-Rafi Bazrafshan: m.bazrafshan@larums.ac.ir).

\begin{abstract}
Background: The prevalence of hookah smoking in the Islamic Republic of Iran is increasing among females, especially in the southern cities.

Aims: The aim of this study was to investigate the factors influencing hookah tobacco smoking among females in the Islamic Republic of Iran.

Methods: In this qualitative study, 52 females who use hookah were selected (25-71 years old) from the cities of Evaz and Gerash and were interviewed. The participants were selected using purposive sampling and the data were gathered using semi-structured interviews. Data analysis was performed using the conventional approach of qualitative content analysis.

Results: Most participants were aged between 25 and 35 years old and 55.8\% were married. Three main themes were identified from the qualitative data including: personal factors, family factors and social factors.

Conclusions: The findings of this study indicate that the reasons for hookah smoking were based on complex interactions between individual, family, and social factors. In order to successfully reduce hookah smoking in females it is necessary to consider an approach that uses these social factors.
\end{abstract}

Keywords: Smoking, hookah, qualitative research, addiction, Iran

Citation: Bazrafshan M; Mansouri A; Delam H; Masmouei B; Shokrpour N. Factors affecting hookah tobacco smoking among females in the Islamic Republic of Iran: a qualitative study. East Mediterr Health J. 2020;26(12):1493-1501. https://doi.org/10.26719/emhj.20.140

Received: 28/01/20; accepted: 13/05/20

Copyright (C) World Health Organization (WHO) 2020. Open Access. Some rights reserved. This work is available under the CC BY-NC-SA 3.0 IGO license (https://creativecommons.org/licenses/by-nc-sa/3.o/igo).

\section{Background}

Tobacco use is one of the leading causes of death, illness and poverty globally. It has been estimated that there are more than 1.3 billion smokers worldwide, of which $82 \%$ live in low- and middle-income countries (1). There are various types of tobacco products such as cigarettes, cigars, bidi, pipes and hookah (2). Much attention has been focused on cigarette smoking but many people, especially in low- and middle-income regions, smoke tobacco using hookah (3). Known as 'ghalyan' in the Islamic Republic of Iran (4), hookah has a historical and cultural origin $(5,6)$. Studies have shown that hookah is more socially acceptable than cigarette smoking and is considered less harmful and addictive (7).

Using tobacco has increased among females of whom many are unaware of the gender-specific health risks associated with tobacco use including cervical cancer, osteoporosis, poor pregnancy outcomes, and early menopause $(8,9)$. In the Islamic Republic of Iran one of the health and social concerns is the increasing consumption of hookah smoking among females. The results of the National Survey of Risk Factors of NonCommunicable Diseases in showed that more than half of female tobacco smokers used hookah (10). Currently, most tobacco smoking studies in the Islamic Republic of Iran have focused on cigarette smoking, with only a few studies conducted on hookah smoking among males and females, and were primarily quantitative rather than qualitative (11-13).

In a study conducted by Baheiraei et al. four main themes were extracted from the qualitative data, including positive attitudes towards hookah smoking, social and family facilitators, and psychosocial needs (14). In a study by Sakineh Dadipoor (15) the themes of climaterelated association or erroneous beliefs was deduced. Thus, a variety of themes have been extracted from a number of qualitative studies attempting to examine the causes of women's tendency to smoke tobacco, especially hookah. Due to the high rate of tobacco use and its health risks and the apparent importance of hookah smoking among females, a qualitative study was deemed to be the best approach to research this area.

\section{Methods}

In this study a qualitative content analysis approach with a conventional qualitative content analysis method was used. Coded classes were extracted directly and inductively from the raw data without formatting the preconceived categories or theoretical views (16). The samples in this study were female current hookah smokers. Inclusion criteria were the subjects' willingness to participate in the study, residents of the cities of Evaz and Gerash, 
familiarity with the Farsi language, and ability to share their experiences about the reasons for hookah smoking. Participants were excluded if they were reluctant to continue participation in the study.

The method of data collection was the use of semistructured interviews between July and September 2019. Interviews began with an explanation of the purpose of the research for the participants, followed by the general open-ended question, "Can you talk about your first experience of hookah smoking?" This was followed by more focused questions on specific issues. If needed, the researcher used exploratory questions such as, "Can you explain more?" or "Can you give an example?" The form and order of the questions were flexible in response to participants' replies. At the end of each interview, the interviewer asked the participants to discuss other important issues that were not addressed during the interview. The time and place of the interview were determined after completing the consent form. With the consent of the participants, audio recordings and field notes were used to enhance the accuracy of the data collection. Interviews were conducted with a researcher.

The mean duration of each interview for participants was approximately 45 minutes. The data collection was finalized after researchers reached saturation. After 47 interviews were conducted, further interviews did not have any extra information to offer.

To analyze the data, researchers first recorded each interview followed by verbatim transcription that was entered into MAXQDA 10 software. Each text was broken down into meaning units, which were grouped together. Finally, based on the content and similarities, the main classes were formed using subcategories. Lincoln and Guba's criteria (2007) were used to improve the accuracy and rigour of the findings (17). After extensive processing of data collection and analysis, a selection of representative samples were checked for accuracy by qualitative research experts, and the initial codes were checked by contributors to increase the credibility of the data in this study.

\section{Ethical considerations}

This study was approved by Larestan University of Medical Sciences Ethics Committee (IR.LARUMS. REC.1398.012).

\section{Results}

Fifty-two interviews were undertaken with female hookah smokers, mean age was $44.53 \pm 12.86$ years. Through data analysis, 39 subcategories and 3 main categories including personal factors, family factors, and social factors were extracted from the data.

\section{Personal factors}

Some participants considered the imitation of other people an effective draw to hookah smoking. A 58-year-old woman said, "Others smoke hookah, I also smoke hookah".

Some participants considered following others as role-models an effective draw to smoking hookah. A

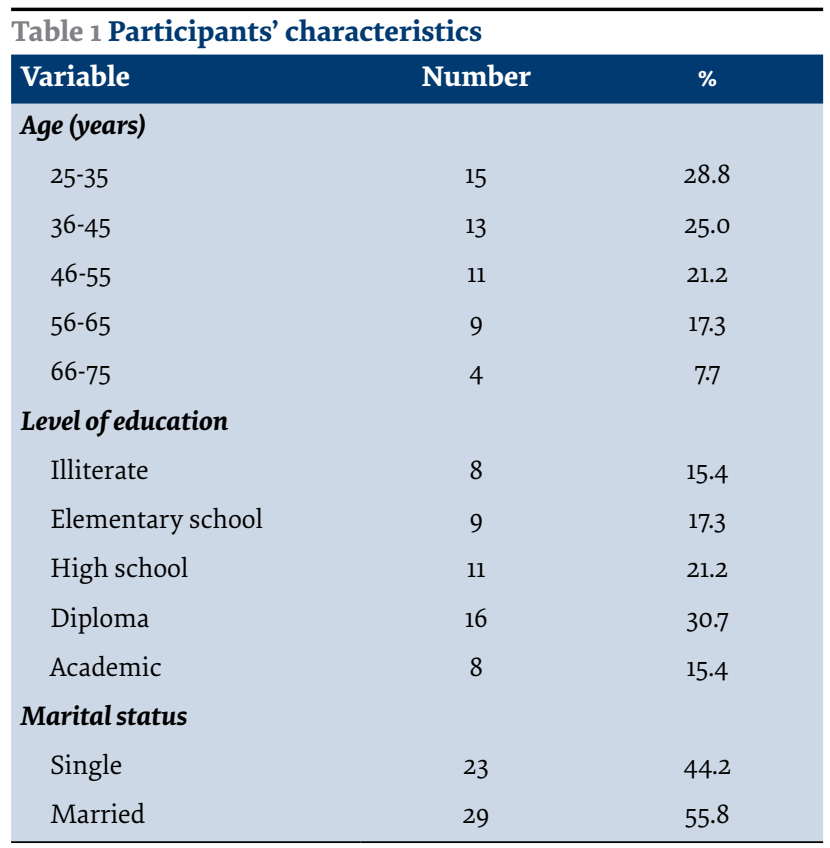

35-year-old woman said, "my aunt had great presence when she smoked a hookah and command over others. I like to be like my aunt".

Believing hookah smoking to be harmless, and even to have healing effects. A 57-year-old woman said, "Many people smoked hookah and lived to 70 and 80 years and more. Even our elderly drank water from the vase of hookah for abdominal pain or they rub its ashes into the throat of a person with a cold".

Dependence on hookah smoking. A 42-year-old woman said, "I just know that if I don't smoke, I have a bad mood, and I feel better when I smoke".

Individuality and attention-seeking were also reasons for smoking hookah. A 39-year-old woman said, "I would like to show off. Hookah is one way to show that I'm fearless".

Curiosity and seeking new experiences. A 47-year-old woman said, "It was interesting for me to experience hookah".

Craving during pregnancy. A 41-year-old woman said, "I had pica during my pregnancy. I found smoking hookah calmed me down. Gradually I became a hookah smoker".

Lack of negative attitudes toward hookah. A 26-yearold woman said, "Hookah didn't affect my health and appearance".

Reducing discomfort and pain. A 40-year-old woman said, "When I'm worried I smoking hookah to give me peace".

Rebellion and feminist sympathies. A 45-year-old woman said, "Why can men do anything but women cannot? They use hookah and do other things. At least I can smoke hookah".

The aspects of fun and pleasure of hookah smoking were another factor factors. A 28-year-old woman said: "When I smoke a hookah, it gives me pleasure and joy. Hookah really entertains me and it is a pleasure means for me".

A feeling of loneliness was one of the personal factors. 


\begin{tabular}{|c|c|}
\hline Themes & Subthemes \\
\hline Personal factors & $\begin{array}{l}\text { Imitation - role-modeling - believing hookah smoking to be harmless - dependence on hookah smoking - exhibitionism - } \\
\text { curiosity - craving during pregnancy - positive attitude towards hookah - relaxation and discomfort alleviation - rebellion } \\
\text { - pleasure - loneliness - temptation - mental illness - preferring flavoured tobacco - being single and higher age of marriage } \\
\text { - Illiteracy and low education level }\end{array}$ \\
\hline Family factors & $\begin{array}{l}\text { Marital problems - family conflicts - responsibility for the preparation of hookah - pretext for family gatherings and meeting } \\
\text { friends - strict household smoking restrictions - Lack of adequate control and awareness from the family - hookah smoking } \\
\text { by family members - gender bias }\end{array}$ \\
\hline Social factors & $\begin{array}{l}\text { Hookah as a household item - traditional view of the role of women in society - easy access to hookah paraphernalia - } \\
\text { availability of online hookah stores - existence of places for hookah smoking - lack of appropriate recreational facilities for } \\
\text { women - poverty - Lack of attention to anti-smoking laws - affordable hookah prices - possibility of hookah smoking in public } \\
\text { places - approval of hookah smoking among women - hookah smoking as a form of social protection for women - Impact of } \\
\text { media - peer pressure }\end{array}$ \\
\hline
\end{tabular}

A 64-year-old woman said: "My husband has gone to work in the Gulf countries. I am alone. The hookah is a friend for me".

The temptation for hookah smoking in the encounter with hookah smokers was one of the personal factors. A 48-year-old woman said:" when I am in a group of people who smoke hookah I also like to do so. I cannot control it".

Having a mental illness. A 49-year-old woman said, "The doctor said I am depressed, I think hookah makes me feel better".

Preferring flavoured tobacco. A 29-year-old woman said, "There is flavoured tobacco that most young people prefer to use. It is attractive".

Being single and later age of marriage. A 44-year-old woman said, "A married woman is busy with home life but I do not have these concerns. For me, hookah smoking is a pretext to being in a family".

Belief that they can quit hookah smoking. A 33-yearold woman said, "Hookah does not cause addiction. Little effort is needed to quit smoking hookah".

Low education level. A 46-year-old woman said, "Illiteracy makes us not understand what doctors and books say about the dangers of hookah".

\section{Family factors}

Marital problems and family conflicts. A 31-year-old woman said, "I have problems with my husband. I smoke hookah to keep calm". A 30-year-old woman said, "I have a disagreement with my husband, so I smoke hookah".

Responsibility for the preparation of the hookah. A 55-year-old woman said: "I remember I was responsible for preparing hookah. I gradually became a hookah smoker".

Hookah smoking was a pretext for family gatherings and meeting friends. A 42-year-old woman said, "I think hookah can bring people together and keep them friendly".

Strict household smoking restrictions (lack of) were instrumental in women smoking hookah. A 28-yearold woman said, "My father who died was not someone who seriously prevented me from smoking hookah".

Lack of sufficient control and familial awareness. A 50-year-old woman said, "My family thought it was normal. They didn't even talk about its dangers. They didn't even know about them".

Hookah smoking by family members. A 49-year-old woman said, "Both my parents smoke hookah. Well, like them, I started smoking hookah".

Gender-bias. A 66-year-old woman said, "My parents just wanted to put the girls into housekeeping. Hookah smoking was a kind of protest against this discrimination".

\section{Social factors}

The traditional view of the role of women. A 31-year-old woman said, "Women in small towns often have to stay at home. I'm bored at home. My fun is hookah".

The availability of hookah as a household item. A 59-year-old woman said, "There is at least one hookah in every home, if they have guests, they serve them hookah".

Accessibility and ease of purchase of hookah. A 71-year-old woman said, "From past to now, it was easy to buy hookah and tobacco".

Some coffee shops or traditional restaurants offer hookah. A 40-years-old woman said, "hookah is essential in tea and coffee houses".

Availability of online hookah stores. A 28-year-old woman said, "You can just go to an online store and order hookah".

The lack of appropriate recreational facilities for women in the city. A 43-year-old woman said, "The city is small. There is no appropriate place for women to have fun".

Poverty. A 36-year-old woman said, "I do not have a wealthy family. The price of the ticket for the swimming pool is high, but hookah is inexpensive".

The freedom to smoke hookah publically. A 55-yearold woman said, "Anyone who wants to smoke hookah can do so anywhere, for example, in the park".

The lack of attention to laws prohibiting smoking in public places. A 53-year-old woman said, "There is a legal ban on tobacco smoking in workplaces and other public spaces, but it is just a slogan".

Approval of hookah smoking among females. A 46-year-old woman said, "There is no opposition to hookah smoking for women".

Believing that hookah smoking by a woman at home 
would help protect her from exposure to risks outside the home. A 63-year-old woman said, "It is better for a woman to stay at home and smoke hookah instead of going out and engage in immoral activities".

The Impact of media on hookah smoking. A 56-yearold woman said, "Hookah smoking was shown in movies. We watched these movies and were impressed".

The influence of peer groups on hookah smoking. A 25-year-old woman said, "In friends gatherings if they smoke hookah and offer it to me I have no choice".

\section{Discussion}

\section{Personal domain}

In the findings of this study 17 codes were observed, which have the highest multiplicity. One participant reported role-modeling in the draw to hookah use. Other studies have shown that imitating others can trigger or encourage continuing cigar smoking $(18,19)$. However, this finding has not been reported in hookah studies. This difference may be due to the fact that smoking cigars/ cigarettes is easier to do in public whereas hookah is a tool that requires a seated environment. Another finding of this study was the use of hookah for self-expression, which was also reported by Baheiraei et al. (20), but Anbarlooi et al. showed that there was a significant relationship between smoking and high school students' self-esteem, yet this relationship was not indicated for hookah smoking (21). However, participants in the present study stated that hookah use is a factor for individuality and self-expression; Mahmoodabad et al. (22) indicated that there was a significant relationship between tobacco use, including hookah, and self-esteem and identity.

In this study it was found a major reasons for using hookah was curiosity, which was supported by Gentzke et al. (23) whereby $14.6 \%$ of people who had never used tobacco and $45.9 \%$ of those who always use tobacco were curious about hookah, and this finding is consistent with those of the present study. In this study, temptation is also mentioned as one of the reasons for using hookah; this finding was also indicated in a study by Jeihooni who examined the causes of hookah use in students (24).

Another personal finding of this study on hookah use was the lack of a negative view of the effects of hookah use on the body, which may have been due to declining levels of knowledge and awareness. It was also observed in a study in the United States of America that most hookah users did not have a high level of literacy (25).

A study of 270 students in Serbia found that the most common reason for students to use hookah was to create a sense of tranquility (26). This finding was also indicated in the present study where participants stated that one of the reasons for using hookah was to induce a feeling of calm and reduce discomfort and pain. Another study conducted on male high school students stated that the reasons for smoking hookah were the need to feel calm and reduce stress (27), but Grinberg's study showed that people who use hookah had a greater perception of pain than non-users, but this was not significant (28).
In the present study the perception of loneliness was indicated as a draw to hookah smoking and supported by other studies that also indicate hookah use is higher among single people and widows (29); this finding could confirm that loneliness as well as being single can lead to hookah use. Reducing discomfort was another reason for the use of hookah, which has been confirmed in several studies $(30,31)$.

Breaking the norms of gender roles and feminist tendencies have been cited as one of the reasons for the use of hookah, which equates to equality with men, but this finding has not been observed in other studies. In addition, one of the reasons for using hookah was association with mental illness, which has been confirmed in various studies $(32,33)$; however, no such finding was found in Goodwin et al. (34), who found that there was no significant relationship between hookah use and mental illness and stress, but there was a significant relationship between cigarette use and mental illness.

Another reason indicated for the increase in the use of hookah is the appeal of flavoured tobacco, which was also found in American society (35). This type of tobacco is more popular among women of childbearing age, and if this category of tobacco is banned then the use of hookah could be reduced (36). One of the reasons found for using hookah in this study was Pica during pregnancy, but was not found in the Kahr et al. study, which found that women considered cigarettes less dangerous than hookah during pregnancy. However, in another study it was observed that women preferred flavoured tobacco hookah during pregnancy such as menthol, believing that it is good for the health of the mother and fetus $(37,38)$.

\section{Family domain}

In the family domain 8 subthemes were extracted and dominated by the factor of imitation. As shown in the Bashirian et al. study, adolescents who have family members using hookah are also more likely to use hookah (27). In addition, other studies have observed that an important factor influencing addiction was inhalation of second-hand smoke (39). In a study conducted in 2016, more than 20000 young people in the United States found that most people who used hookah frequently lived with an addicted hookah smoker (40).

Considering that hookah smoking is frequently seen as integral to family and friends gatherings, a qualitative study by Baheiraei et al. which looked at the prevalence of hookah use in women, supported the current study finding that hookah preparation was a factor in hookah smoking addiction. It was also observed that husbands and wives played an important role in women's addiction to hookah, suggesting that education about the risks should also be aimed at the family level (5).

Hookah smoking is also suggested as a cause of family relationship problems, which is in line with the Bhat et al. study (41). However, another study looked at it from a different approach and reported that the observed causes of problems in family and marital relationships due to hookah smoking is the resultant prevalence of bad breath 
(42). Familial disapproval of smoking cigarettes was also observed as a reason for smoking hookah. In this regard, a study reported that disapproval of women smoking cigarettes was prevalent in the Iranian population, but less disapproval of smoking hookah, which is consistent with the results of the present study (43).

Other factors influencing the draw to hookah smoking among women include reduced supervision and control by the family. This finding was also observed in the Farideh et al. study, which reported children who were of a low socioeconomic and educational level were more exposed to tobacco smoking (44).

\section{Social domain}

In the social domain 13 codes were extracted. A primary reason observed for using hookah was the lack of entertainment for women, which supports studies indicating that the draw to smoking hookah in young females was its entertainment and social interaction value (45). These findings are in line with the results of the present study highlighting the lack of appropriate recreational facilities for women in the social domain (46). In a qualitative study on 37 Swedish adolescents, reasons for using hookah were meeting friends, being accepted by a group, or using hookah as a criterion for admission into a group. Moreover, participants did not have a negative concerning hookah smoking (47), and related studies have indicated that there was a strong link between hookah use and having friends who are addicted to hookah or smoking cigarettes (48).

Not viewing hookah smoking as harmful has been observed in various studies $(46,49)$ as well as ease of access due to moderate pricing as important reasons for addiction $(46,50)$ and the lack of any legal restriction to the use of hookah (51). Poverty was also found to be a cause for hookah addiction and supported by the Salloum et al. study (52), which indicated that loack of legal controls over access to hookah is a contributing factor to addiction $(51,53)$.

In a qualitative study published in 2019 (54), the tendency of individuals to use hookah was divided into three areas: attitude, mental norm, and receiving controlling behaviours. These three areas included 9 subcategories, and the results of this study showed that in hookah addiction, people maintained a positive attitude towards hookah and consider it harmless when compared to cigarettes, and is considered a suitable substitute. In addition, acceptance in the community and availability were mentioned in the social domain, which is in line with the findings of the present study. However, the current study differed in the manner of classifying the factors influencing hookah addiction.

Another study conducted in Fasa in 2015 (24) examined students' knowledge and attitudes toward hookah use, which observed that more than $80 \%$ of students who held intentions to give it up for health reasons, yet continued to use it. This underlies the belief that hookah smoking was not addictive, but rather its use could reduce anxiety. This observation is included in the personal domain of the current study.

One finding in the current study remains unique, which is the view that hookah smoking can protect women from high-risk behaviours and addiction to more dangerous substances outside the home. This finding is consistent with Weina Qu et al. (55), which showed how stress can increase risk taking and aggressive behaviour.

The existence of centres outside home for hookah use was also observed as a contributing factor to hookah addiction among women; in contrast, a study found that hookah use was the most common behaviour within the home for users in the United States (40). Another study in Iraq found that hookah was mostly used in coffee shops (56) while in the Islamic Republic of Iran, the use of hookah in traditional restaurants is common (57), thus there are cultural dimensions to this phenomenon. Finally, an important reason for using hookah is the power of the media, which has been confirmed in a number of studies, promoting the use of hookah significantly $(58,59)$.

\section{Conclusion}

One of the strengths of this study is the qualitative extraction of various factors shown to influence the behaviour and attitudes of women towards hookah smoking. These factors were classified into three themes: personal, family and social. These factors were considered from several perspectives, including childhood and adolescence, such as exposure to preparation of hookah at home or having parents smoking hookah, as well as experiencing loneliness in adulthood. Despite the psychological contributing factors, such as mental illness, physical aspects are also prevalent such as Pica during pregnancy. Some factors are also related to the individual, such as curiosity or exhibitionism, as well as social ignorance of the harm of hookah smoking. The role of society also manifests itself in factors such as the lack of appropriate recreational facilities for women, or poverty. Certain factors transcend local or national borders such as the media, while current legislation fails to exert sufficient control of access to hookah.

A sense of gender equality has encouraged some women to take up hookah smoking, while at the same time there is an opinion that hookah smoking among women prevents them from being exposed or tempted by inappropriate behaviours beyond the control of the family. The reasons are numerous and indicate that influences behind women taking up hookah smoking are individual and not necessarily predictable. Qualitative studies such as the present study draw data directly from women themselves, making it possible to plan and take appropriate measures on an individual, family and social level. Due to the wide range of reasons for using hookah among women, it requires comprehensive cooperation from different sections of society and government to reduce this harmful behaviour. 


\section{Acknowledgement}

The authors would also like to thank all the research participants who have contributed to the study.

Funding: Faculty of Medical Sciences, Larestan University (code number: 1398-003).

Competing interests: None declared.

\section{Étude qualitative sur les facteurs influençant le tabagisme par houka chez les femmes en République islamique d'Iran}

\section{Résumé}

Contexte : La prévalence du tabagisme par houka en République islamique d'Iran augmente chez les femmes, en particulier dans les villes du sud.

Objectifs : l'objectif de la présente étude était d'étudier les facteurs influencant le tabagisme par houka chez les femmes en République islamique d'Iran.

Méthodes : Dans cette étude qualitative, 52 femmes sélectionnées qui fumaient la houka (âgées de 25 à 71 ans) dans les villes d'Evaz et de Gerash ont été interrogées. Les participantes ont été sélectionnées sur la base d'un échantillonnage ciblé et les données ont été recueillies dans le cadre d'entretiens semi-structurés. L'analyse des données a été réalisée selon l'approche conventionnelle d'analyse qualitative du contenu.

Résultats : La plupart des femmes avaient entre 25 et 35 ans. En termes de statut marital, 55,8\% étaient mariées. Trois thèmes principaux ont été identifiés à partir des données qualitatives, à savoir : les facteurs personnels, les facteurs familiaux et les facteurs sociaux.

Conclusions : Les résultats de cette étude indiquent que les raisons de l'utilisation de la houka étaient les interactions complexes entre les facteurs individuels, familiaux et sociaux. Pour réussir à réduire le tabagisme par houka chez les femmes, il est nécessaire de tenir compte les facteurs sociaux.

$$
\begin{aligned}
& \text { العوامل المؤثّة في تدخين تبغ الشيشة بين الإناث في جمهورية إيران الإسلامية: دراسة نوعيّة }
\end{aligned}
$$

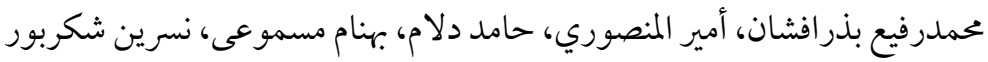

$$
\begin{aligned}
& \text { الخلاصة } \\
& \text { الخلفية: يتز ايد معدّل انتشار تدخين الشيشة في جمهورية إيران الإسلامية بين الإناث، لا سيّما في المدن الجنوبية. }
\end{aligned}
$$

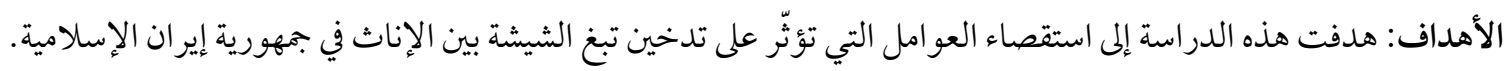

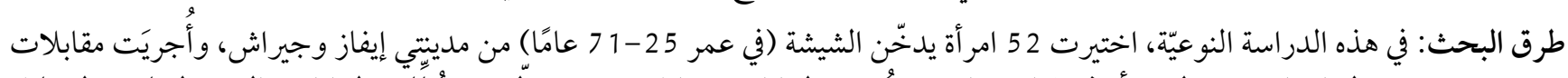

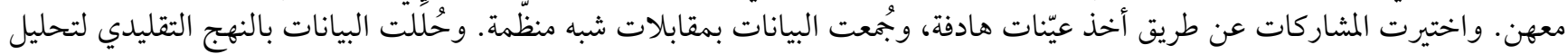

$$
\begin{aligned}
& \text { المحتوى النوعي. }
\end{aligned}
$$

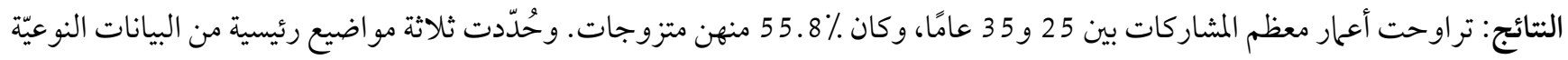

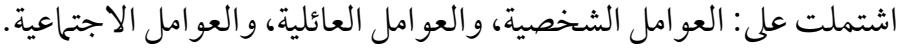

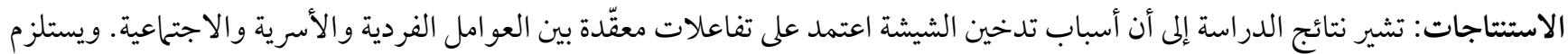

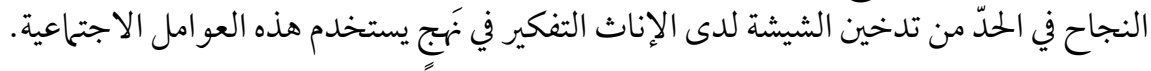




\section{References}

1. Gaziano TA, Pagidipati N. Scaling up chronic disease prevention interventions in lower- and middle-income countries. Annu Rev Public Health. 2013;34:317-35.

2. O'Connor RJ. Non-cigarette tobacco products: what have we learnt and where are we headed? Tob Control. 2012;21(2):181-90.

3. Maziak W, Fouad F, Asfar T, Hammal F, Bachir E, Rastam S, et al. Prevalence and characteristics of narghile smoking among university students in Syria. Int J Tuberc Lung Dis. 2004;8(7):882-9.

4. Saadat S, Karbakhsh M. Association of waterpipe smoking and road traffic crashes. BMC public health. 2010;10(1):639.

5. Baheiraei A, Shahbazi Sighaldeh S, Ebadi A, Kelishadi R, Majdzadeh R. The Role of family on hookah smoking initiation in women: a qualitative study. Global J Health Science. 2015;7(5):1-10.

6. Maziak W. The waterpipe: an emerging global risk for cancer. Cancer Epidemiol. 2013;37(1):1-4.

7. Martinasek MP, Haddad LG, Wheldon CW, Barnett TE. Beliefs and attitudes associated with hookah smoking among a United States college population. Respir Care. 2017;62(3):370-9.

8. Samet JM, Yoon S-Y. Gender, women, and the tobacco epidemic. Geneva: World Health Organization; 2010.

9. Kaleta D, Usidame B, Polanska K. Tobacco advertisements targeted on women: creating an awareness among women. Central Eur J Public Health. 2011;19(2):73.

10. Meysamie A, Ghaletaki R, Haghazali M, Asgari F, Rashidi A, Khalilzadeh O, et al. Pattern of tobacco use among the Iranian adult population: results of the national Survey of Risk Factors of Non-Communicable Diseases (SuRFNCD-2007). Tob Control. 2010;19(2):125-8.

11. Rahmanian K JA, Khalouei A. Determinants of cigarette smoking among high school students in Jahrom city. Paramedics of Tehran University of Medical Sciences. 2011;4(1\&2):88-96.

12. Roohafza H, Sadeghi M, Shahnam M, Bahonar A, Sarafzadegan N. Perceived factors related to cigarette and waterpipe (ghelyan) initiation and maintenance in university students of Iran. Int J Public Health. 2011;56(2):175-80.

13. Sabahy A-R, Divsalar K, Nakhaee N. Attitude of university students towards waterpipe smoking: study in Iran. Addiction \& health. 2011;3(1-2):9.

14. Baheiraei A, Shahbazi Sighaldeh S, Ebadi A, Kelishadi R, Majdzadeh R. Factors that contribute in the first hookah smoking trial by women: a qualitative study from Iran. Iran J Public Health. 2015;44(1):100-10.

15. Dadipoor S, Kok G, Aghamolaei T, Ghaffari M, Heyrani A, Ghanbarnezhad A. Explaining the determinants of hookah consumption among women in southern Iran: a qualitative study. BMC Public Health. 2019;19(1):1-13.

16. Hsieh HF, Shannon SE. Three approaches to qualitative content analysis. Qualitat Health Res. 2005;15(9):1277-88.

17. Streubert HJ, Carpenter DR. Qualitative research in nursing. Advancing the humanistic imperative. 4 ed: Philadelphia: Lippincott Williams \& Wilkins; 2007.

18. Harakeh Z, Engels RC, Van Baaren RB, Scholte RH. Imitation of cigarette smoking: an experimental study on smoking in a naturalistic setting. Drug and Alcohol Dependence. 2007;86(2-3):199-206.

19. Luhulima R. The imitation of smoking behavior during real life and digital interaction. Faculty of Social and Behavioural Sciences theses, Utrech University 2012.

20. Baheiraei A, Sighaldeh SS, Ebadi A, Kelishadi R, Majdzadeh SR. Psycho-social needs impact on hookah smoking initiation among women: a qualitative study from Iran. Int J Prevent Med. 2015;6.

21. Anbarlouei M, Sarbakhsh P, Dadashzadeh H, Ghiasi A, Ataieasl M, Dorosti A, et al. Cigarette and hookah smoking and their relationship with self-esteem and communication skills among high school students. Health Promotion Perspectives. 2018;8(3):230.

22. Mahmoodabad SSM, Khajedehi Z, Mahmoodabadi HZ, Fallahzadeh H. Investigating the factors related to substance use in the Iranian high school students using the Positive Youth Development Model. Iran J Psychiat Behav Sciences. 2017;11(2).

23. Gentzke AS, Wang B, Robinson JN, Phillips E, King BA. Peer reviewed: Curiosity about and susceptibility toward hookah smoking among middle and high school students. Preventing Chronic Disease. 2019;16.

24. Jeihooni AK, Khiyali Z, Kashfi SM, Kashfi SH, Zakeri M, Amirkhani M. Knowledge and attitudes of university students towards hookah smoking in Fasa, Iran. Iran J Psychiat Behav Sciences. 2018;12(1).

25. Salloum RG, Thrasher JF, Kates FR, Maziak W. Water pipe tobacco smoking in the United States: findings from the National Adult Tobacco Survey. Preventive Medicine. 2015;71:88-93.

26. Vapljanin MZ, Kocović AG, Milosavljević MN, Stefanović SM. Factors influencing hookah smoking in high school students. Acta facultatis medicae Naissensis. 2018;35(2):114-24.

27. Bashirian S, Barati M, Mohammadi Y, Mostafaei H. Factors associated with hookah use among male high school students: the role of demographic characteristics and hookah user and non-user prototypes. J Res Health Sciences. 2016;16(4):217-23.

28. Grinberg A. Subjective well-being and hookah use among adults in the United States: a nationally-representative sample. Drug and Alcohol Dependence. 2015;153:242-9.

29. Soulakova JN, Pham T, Owens VL, Crockett LJ. Prevalence and factors associated with use of hookah tobacco among young adults in the US. Addictive Behaviors. 2018;85:21-5. 
30. Roohafza H, Kasaei Z, Heidari K, Omidi R, Alinia T, Naji M, et al. Better view on attitudes and perceived parental reactions behind waterpipe smoking among Iranian students. J Res Med Sciences: the official journal of Isfahan University of Medical Sciences. 2015;20(11):1032.

31. Braun RE, Glassman T, Wohlwend J, Whewell A, Reindl DM. Hookah use among college students from a Midwest University. J Comm Health. 2012;37(2):294-8.

32. Ramji R, Arnetz BB, Nilsson M, Wiklund Y, Jamil H, Maziak W, et al. Waterpipe use in adolescents in Northern Sweden: Association with mental well-being and risk and health behaviours. Scan J Public Health. 2018;46(8):867-76.

33. Hamadeh RR, Al Ansari A, Jahrami H, Al Offi A. Cigarette and waterpipe smoking among adult patients with severe and persistent mental illness in Bahrain: a comparison with the National Non-communicable Diseases Risk Factors Survey. BMC research notes. 2016;9(1):77.

34. Goodwin RD, Grinberg A, Shapiro J, Keith D, McNeil MP, Taha F, et al. Hookah use among college students: prevalence, drug use, and mental health. Drug and Alcohol Dependence. 2014;141:16-20.

35. Owens VL, Ha T, Soulakova JN. Widespread use of flavored e-cigarettes and hookah tobacco in the United States. Preventive Medicine Reports. 2019;14:100854.

36. Scott-Sheldon LA, Stroud LR. Preferences and perceptions of flavored hookah tobacco among US women. Am J Health Behav. 2018;42(3):37-46.

37. Kahr MK, Padgett S, Shope CD, Griffin EN, Xie SS, Gonzalez PJ, et al. A qualitative assessment of the perceived risks of electronic cigarette and hookah use in pregnancy. BMC Public Health. 2015;15(1):1273.

38. Stroud L, Werner E, Matteson K, Carey M, St Helen G, Eissenberg T, et al. Waterpipe (hookah) tobacco use in pregnancy: use, preferences and perceptions of flavours. Tob Control. 2020;29(Suppl 2):s62-s71.

39. Abdollahpour I, Mansournia MA, Salimi Y, Nedjat S. Lifetime prevalence and correlates of smoking behavior in Iranian adults' population; a cross-sectional study. BMC public health. 2019;19(1):1-11.

40. Agaku I, Odani S, Armour B, Glover-Kudon R. Social aspects of hookah smoking among US youth. Pediatrics. 2018;142(2):e20180341.

41. Bhat BA, Kumar M, Mushtaq S. Smoking patterns among people in Jammu region of Jammu and Kashmir State. The IIOAB Journal. 2013;4(2):36.

42. Azodi F, Sharif F, Azodi P, Shirazi ZH, Khalili A, Jahanpour F. The reasons of tendency toward hookah smoking among teens and youth in Iran-A qualitative study. J Pharm Sciences Res. 2017;9(9):1642-6.

43. Kelishadi R, reza Mokhtari M, Tavasoli AA, Khosravi A, Ahangar-Nazari I, Sabet B, et al. Determinants of tobacco use among youths in Isfahan, Iran. Int J Public Health. 2007;52(3):173-9.

44. Shiva F, Padyab M. Smoking practices and risk awareness in parents regarding passive smoke exposure of their preschool children: A cross-sectional study in Tehran. Ind J Med Sciences. 2008;62(6):228-35.

45. Sohrabzadeh M, Parnian l. Qualitative studies smoking hookah among girls and young women (case study: Shiraz City). 2015.

46. Baheiraei A, Sighaldeh SS, Ebadi A, Kelishadi R, Majdzadeh R. Factors that contribute in the first hookah smoking trial by women: A qualitative study from Iran. Iran J Public Health. 2015;44(1):100.

47. Ramji R, Nilsson M, Arnetz B, Wiklund Y, Arnetz J. Taking a stand: An untapped strategy to reduce waterpipe smoking in adolescents. Substance Use \& Misuse. 2019;54(3):514-24.

48. Abbasi-Ghahramanloo A, Rahimi-Movaghar A, Zeraati H, Safiri S, Fotouhi A. Prevalence of hookah smoking and its related factors among students of Tehran University of Medical Sciences, 2012-2013. Iran J Psychiat Behav Sciences. 2016;10(2).

49. Labib N, Radwan G, Mikhail N, Mohamed MK, El Setouhy M, Loffredo C, et al. Comparison of cigarette and water pipe smoking among female university students in Egypt. Nicotine \& Tobacco Research. 2007;9(5):591-6.

50. Hammal F, Wild TC, Nykiforuk C, Abdullahi K, Mussie D, Finegan BA. Waterpipe (hookah) smoking among youth and women in Canada is new, not traditional. Nicotine \& Tobacco Research. 2016;18(5):757-62.

51. Bahelah R. Waterpipe tobacco labeling and packaging and World Health Organization Framework Convention on Tobacco Control (WHO FCTC): a call for action. Addiction. 2014;109(2):333.

52. Salloum RG, Thrasher JF, Getz KR, Barnett TE, Asfar T, Maziak W. Patterns of waterpipe tobacco smoking among US young adults, 2013- 2014. Am J Prevent Med. 2017;52(4):507-12.

53. Griffiths MA, Harmon TR, Gilly MC. Hubble bubble trouble: the need for education about and regulation of hookah smoking. Journal of Public Policy \& Marketing. 2011;30(1):119-32.

54. Pas Haeypoor S, Negarandeh R, Nikpeyma N, Abadi ZAM. Determinants of intentions toward smoking hookah in Iranian adolescents based on the theory of planned behavior. Iran J Public Health. 2019;48(7):1317-25.

55. Ge Y, Qu W, Jiang C, Du F, Sun X, Zhang K. The effect of stress and personality on dangerous driving behavior among Chinese drivers. Accident Analysis \& Prevention. 2014;73:34-40.

56. Othman N, Kasem AO, Salih FA. Waterpipe smoking among university students in Sulaimaniyah, Iraqi Kurdistan: prevalence, attitudes, and associated factors. Tanaffos. 2017;16(3):225. 
57. Hessami Z, Masjedi M, Sharifi H, Emami H, Kazempour M, Jamaati H. Characteristics of Iranian hookah smokers aged 15 and above: a primary report. Health Scope. 2016;5(4).

58. Link AR, Cawkwell PB, Shelley DR, Sherman SE. An exploration of online behaviors and social media use among hookah and electronic-cigarette users. Addictive Behaviors Reports. 2015;2:37-40.

59. Primack BA, Rice KR, Shensa A, Carroll MV, DePenna EJ, Nakkash R, et al. US hookah tobacco smoking establishments advertised on the internet. Am J Prevent Med. 2012;42(2):150-6. 